\title{
The Role of Glycogen Synthase Kinase 3- $\beta$ in Immunity and Cell Cycle: Implications in Esophageal Cancer
}

\author{
Shegan Gao · Jonathan Brown · Huizhi Wang • \\ Xiaoshan Feng
}

Received: 31 December 2012/Accepted: 6 November 2013/Published online: 26 November 2013

(c) L. Hirszfeld Institute of Immunology and Experimental Therapy, Wroclaw, Poland 2013

\begin{abstract}
Esophageal cancer (EC) is one of the most aggressive gastrointestinal malignancies, possessing an insidious onset and a poor prognosis. Numerous transcription factors and inflammatory mediators have been reported to play a pivotal role in the initiation and progression of this cancer. However, the specifics of the signaling network responsible for said factors, especially which elements are the critical regulators, are still being elucidated. Glycogen synthesis kinases 3 (GSK3) $\beta$ was originally regarded as a kinase regulating glucose metabolism. Accumulating evidence demonstrated that it also played an essential role in a variety of cellular processes including proliferation, differentiation, inflammation, motility, and survival by regulating various transcription factors such as c-Jun, AP-1, $\beta$-catenin, CREB, and NF- $\kappa B$. Aberrant regulation of GSK3 $\beta$ has been shown to promote cell growth in some cancers, while suppressing it in others, and thus may play an important role in the development of EC. This review will discuss our current understanding of
\end{abstract}

S. Gao $\cdot$ X. Feng $(\bowtie)$

Department of Oncology, Cancer Institute, The First Affiliated Hospital of Henan University of Science and Technology, 24 Jinghua Road, Jianxi Qu, Luoyang 471003, China e-mail: samfeng137@hotmail.com

\section{J. Brown}

Department of Microbiology and Immunology, University of Louisville School of Medicine, Louisville, KY 40202, USA

\section{H. Wang $(\bowtie)$}

Oral Health and Systemic Disease Research Group, University of Louisville School of Dentistry, 501 South Preston Street, Room 263C, Louisville, KY 40202, USA

e-mail: hhwang01@louisville.edu
GSK3 $\beta$ signaling, and its control of the expression and activation of various transcription factors that mediate the inflammatory response. We will also explore some of the known mediators of EC progression, and based on current literature, elucidate the potential roles and implications of GSK3 in this disease.

Keywords Esophageal cancer - Inflammation · GSK3 · PI3K · Inflammatory cytokines

\section{Introduction}

Esophageal cancer (EC) is regarded as one of the most aggressive malignant tumors of the gastrointestinal tract. Whereas the majority of cases occur in Asia, especially in some provinces of central China like Henan, recent studies have shown that the frequency of new cases of this neoplasm is projected to be at a $10 \%$ annual increase in Western Europe and the USA (Blot et al. 1991; Crew and Neugut 2004). As the eighth most common cancer worldwide and the sixth leading cause of cancer deaths, this malignant tumor is characterized by rapid development and generally poor prognosis (Coleman et al. 2003). For the patients with inoperable cancer, the median survival is estimated between 13 and 29 months. Even when an esophagectomy is performed, the five-year survival of EC patients is only 10-20\% (Coleman et al. 2003). The astonishing high mortality of EC could be due to the relatively late stage of diagnosis, the rapid progression of the tumor, and the lack of understanding of the underlying cellular mechanism of the disease (Vallbohmer and Lenz 2006). Various environmental factors including poor oral hygiene, diet, viral infection, and chemical exposure (Eslick 2010; Scully and Bagan 2009) have been reported 
to be risk factors. Accumulating evidence suggests that the alternation of transcription factors (TFs) activity and expression of multiple inflammatory mediators play a pivotal role in neoplastic transformation and tumorigenesis of EC. In this regard, TFs led to the expression of various genes (either pro- or anti-tumorigenesis) that are implicated in each stage of cancer development, mainly through controlling cell cycle and apoptosis. The inflammatory mediators could exert their effects on tumorigenesis directly or by modifying the activity of TFs. To date, how these TFs and inflammatory mediators are regulated, and which are the molecular key players is still poorly understood. Therefore, identifying the key players regulating these factors and elucidating the underlying interactions of this network will be beneficial to design the optimal therapeutic strategy for EC patients. Our and other studies (Jope et al. 2007; Jope and Johnson 2004; Wang et al. 2008, 2011a, b) demonstrated that glycogen synthesis kinases 3 (GSK3) is involved in many physiological and pathological processes including proliferation, differentiation, motility, and survival through regulating the activity of TFs and production of inflammatory mediators, which suggested that GSK3 could be a potential molecular target in the development of EC.

\section{What Is GSK3 and How Does It Work?}

GSK3 was originally isolated from skeletal muscle and is a critical enzyme involved in glycogen metabolism (Embi et al. 1980; Woodgett and Cohen 1984). Recent studies have identified GSK3 as a point of convergence for numerous cell-signaling pathways involved in a multitude of cellular physiological processes including development, cell cycle, differentiation, motility, microtubule function, apoptosis, adhesion, and inflammation (Doble and Woodgett 2003; Jope and Johnson 2004; Kockeritz et al. 2006; Wang et al. 2011c) (Fig. 1). The incredible number of cellular processes controlled by GSK3, either directly or indirectly, has been shown to be due to its ability to posttranslationally modify TFs via its ability to phosphorylate consensus site-specific serine or threonine residues (Ali et al. 2001; Jope and Johnson 2004) (Fig. 1). Due to the ability of GSK3 to impact numerous intracellular signaling pathways, it is not surprising that the disregulation of GSK3 has been shown to be involved in the initiation or progression of several cancers. GSK3 $\beta$ has been shown to promote the growth of some cancers, e.g. pancreatic cancer, myeloma cancer, and colorectal cancer, while suppressing growth in others, e.g. lung cancer, EC, and breast cancer (Garcea et al. 2007; Kang et al. 2008; Zhou et al. 2008).

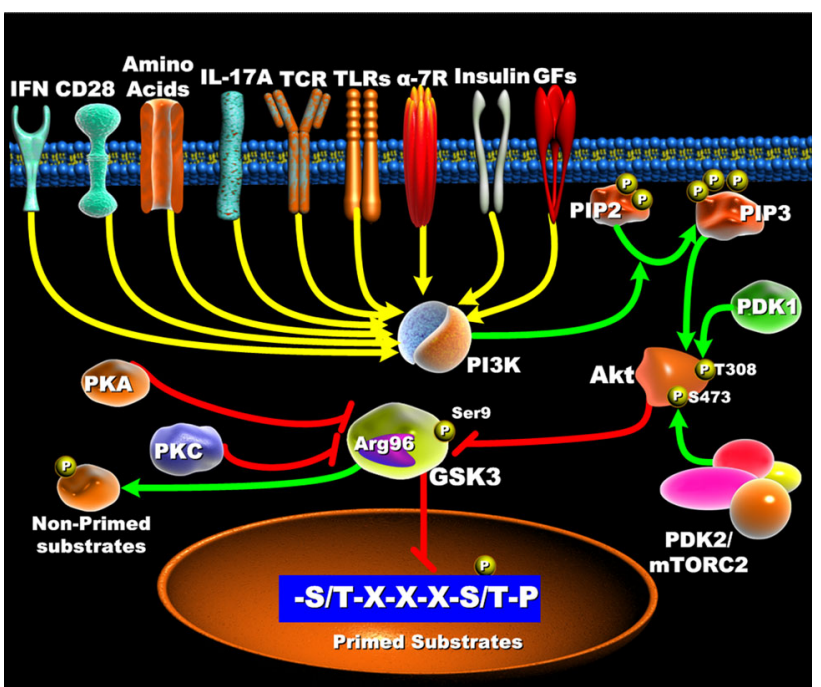

Fig. 1 Regulation of GSK3 and its substrates specificity. Amino acids, growth factors, TLRs, T cell receptor (TCR), CD28, and cytokine receptors have been shown to mediate the phosphoinactivation of GSK3. Activation of PI3K results in the generation of PIP3 that allows for the recruitment of Akt via its pleckstrin homology domain. Full activation of Akt occurs when it is phosphorylated at threonine 308 by PDK1 and serine 473 by PDK2/mTORC2. Upon activation, Akt can phosphorylate GSK3 $\beta$ (Ser9) that results in its inactivation. PKC and PKA also can phosphoinactivate GSK3. Active GSK3 exhibits a 100-1,000-fold increase in substrate specificity for pre-primed substrates, as compared to nonprimed substrates. N-terminal phosphorylation of GSK3 $\beta$ (Ser9) acts as a pseudo-substrate for the phosphate-binding site (arginine 96) of GSK $3 \beta$ and competes with pre-primed, but not non-primed substrates

There are two major GSK3 isoforms, GSK3 $\alpha$ and $\beta$, that are encoded by distinct genes and endowed with different functions in mammalian cells (Woodgett 1990). In addition, an alternative splice variant of GSK3 $\beta$, referred to as GSK3 32 , has also been identified in the brains of mice, rats, and humans (Mukai et al. 2002). GSK3 is a constitutively active serine/threonine kinase under basal cellular conditions and phosphorylation results in a decrease of its activity. Initial studies assessing the cell-signaling pathways activated by insulin identified that insulin receptor signaling resulted in the activation of the phosphoinositide 3 kinase (PI3K) pathway and the subsequent phosphoinactivation of GSK3 $\alpha$ (serine 21) or GSK3 $\beta$ (serine 9) by Akt (Cross et al. 1994). Other cellular stimuli including growth factors (Brady et al. 1998), phorbol esters (Shaw and Cohen 1999), amino acids (Peyrollier et al. 2000), Toll-like receptors (TLRs) (Wang et al. 2008), T cell receptor (Garcia et al. 2008), CD28 (Garcia et al. 2008), and interleukin (IL) receptors (Garcia et al. 2009) have also been shown to phospho-inactivate GSK3 $\alpha$ (serine 21), GSK3 $\beta$ (serine 9), or both (Fig. 1). Phosphorylation of GSK3 can be mediated by Akt (Martin et al. 2005), P70S6K (Peyrollier et al. 2000), P90RSK (Saito et al. 
1994b), PKC isoforms (Fang et al. 2002), or PKA (Sheridan et al. 2002) (Fig. 1).

It has been shown that the activity of GSK3 $\beta$ is regulated by its phosphorylation, localization, and interaction with regulatory proteins and multiple-protein complexes (Ali et al. 2001; Jope et al. 2007). GSK3 $\beta$ prefers to phosphorylate substrates that are pre-primed (pre-phosphorylated) on a serine or threonine located around a five amino acid consensus sequence corresponding to serine/threonine $-\mathrm{X}-\mathrm{X}-$ $\mathrm{X}$ - serine/threonine-P. The first serine or threonine in this motif is the residue to be phosphorylated by GSK3 $\beta$, X can be any amino acid, and the last serine- or threonine-P is the pre-primed (pre-phosphorylated) residue (Fiol et al. 1987) (Fig. 1). The preferential phosphorylation of pre-primed (pre-phosphorylated) substrates by GSK3 $\beta$ has been shown to increase substrate phosphorylation efficiency by more than 100-1,000-fold, as compared to non-primed substrates (Thomas et al. 1999). This characteristic of GSK3 $\beta$ to prefer pre-primed (pre-phosphorylated) substrates also plays a role in its inactivation by serine phosphorylation. Studies by Frame et al. (2001) demonstrated that mutating arginine 96 to alanine abrogated the ability of GSK $3 \beta$ to phosphorylate preprimed (pre-phosphorylated) substrates. Interestingly, the arginine 96 mutant of GSK3 $\beta$ could still phosphorylate nonprimed substrates and this activity was not affected by Aktmediated serine 9 phosphorylation of GSK3 $\beta$. These findings demonstrated that the N-terminal phosphorylation of GSK3 $\beta$ on serine 9 acted as a pseudo-substrate for the phosphate-binding site (arginine 96) of GSK3 $\beta$ and competed for the binding to arginine 96 with pre-phosphorylated substrates.

\section{Potential Involvement of GSK3 in the Progression of EC via the Regulation of Inflammatory Mediators}

It has been reported that GSK3 $\beta$ plays a central role in inflammation control by regulating the innate and adaptive immune responses (Wang et al. 2011c). Since the pivotal role of inflammation in the development of cancer has been established, we will discuss the effect of inflammation in the development of EC and how GSK3 $\beta$ contributes to this process via regulating the activity and expression of inflammation mediators.

\section{Esophageal Cancer and Inflammation}

Inflammation is a fundamental physiological process and is regarded as a primary host response to maintain tissue homeostasis upon tissue stressors such as infection or tissue damage. The close relationship between inflammation and tumorigenesis has been reported repeatedly by experimental, clinical, and epidemiological studies (Li et al.
2011; Patel and Woodgett 2008). As early as in nineteenth century, Dr. Virchow observed the infiltration of leukocytes into tumors (Balkwill and Mantovani 2001), and since then, an extensive body of literature has elucidated the contribution of inflammation in the initiation, growth, and metastasis of tumors (Colotta et al. 2009). Chronic inflammation was reported to initiate cancer by generating genotoxic stress, promoting cancer by inducing cellular proliferation and accelerating cancer development by enhancing angiogenesis and tissue invasion (Grivennikov et al. 2010; Li et al. 2011). Epidemiological studies have shown up to $25 \%$ of human cancers were caused by inflammation, and inflammatory diseases in different organs can predispose one to the initiation and development of certain types of cancers (Hussain and Harris 2007). The strong association between inflammation and carcinogenesis has been observed in the liver, lung, prostate, ovaries, and especially gastroenterological organs. For instance, patients with chronic hepatitis $\mathrm{B}$ or $\mathrm{C}$ have a high risk of developing hepatocellular carcinoma. Chronic Helicobacter pylori gastritis is the most frequent and important causative factor for gastric cancer (Bornschein et al. 2010; Ernst and Gold 2000). Inflammatory bowel disease patients are predisposed to colon cancer (Itzkowitz and Yio 2004). Reflux esophagitis and Barrett's metaplasia are considered important factors in the development of esophageal adenocarcinoma (Zhang et al. 2009).

Inflammation is involved in the promotion and development of esophageal cancers either by regulating the activity and expression of risk factors (TFs, inflammation mediators, etc.) or inducing epigenetic alternation such as methylation of target genes. Take cytokines as an example, the nature and magnitude of cytokine production have been demonstrated to promote EC development. Fitzgerald et al. (2002a, b) analyzed cytokine expression and infiltration of inflammatory cells in different stages of EC and suggested that inflammatory mediators play an essential role during the progression of reflux esophagitis to Barrett's esophagus. Studies by Moons et al. (2008) also demonstrated the influences of cytokine gene polymorphisms on the development of esophageal cancer. They reported that a genetic profile predisposing an individual to a strong pro-inflammatory host response is associated with EC. Due to the increasing evidence demonstrating that GSK3 orchestrates the regulation of inflammatory mediators and several other cell cycle regulators, we will discuss the potential influence of GSK3 in the development of EC via regulating inflammatory mediators, apoptosis, TFs, and cell cycle (Figs. 2, 3, 4).

Regulation of GSK3 in Inflammatory Responses

As a substrate of the PI3K/Akt pathway, our lab has demonstrated that GSK3 plays a critical role in 


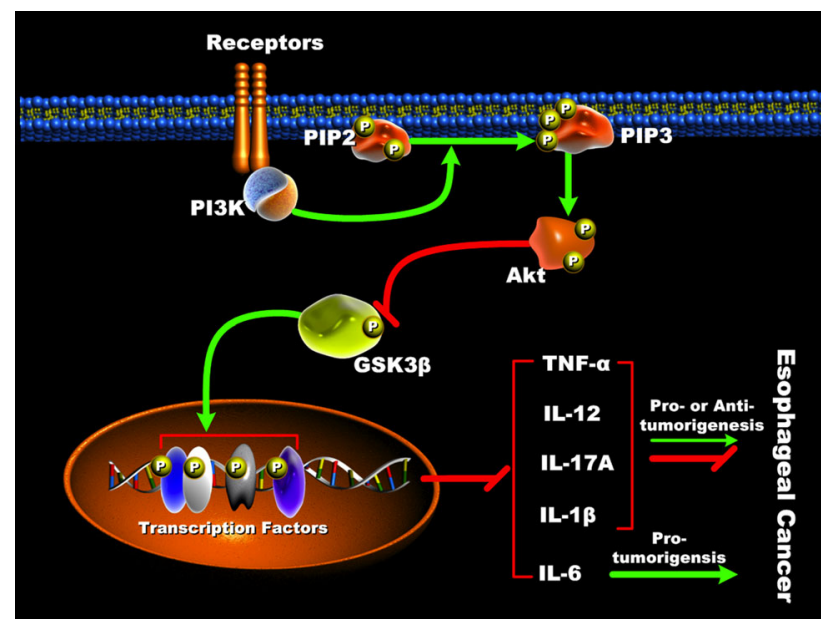

Fig. 2 Active GSK3 promotes an inflammatory cytokine profile. Different stimuli mediate inactivation of GSK3, and subsequently, suppress the production of pro-inflammatory cytokine production by regulating the activity of various transcription factors. While it has repeatedly been shown that chronic inflammation promotes tumorigenesis, several of these pro-inflammatory cytokines, namely TNF- $\alpha$, IL-12, and IL-1 $\beta$, have been shown to inhibit tumor growth and disease progression. Thus, low GSK3 activity may prevent tumorigenesis by limiting inflammation, but once the disease has been established, modulating GSK3 activation may be useful in controlling disease progression

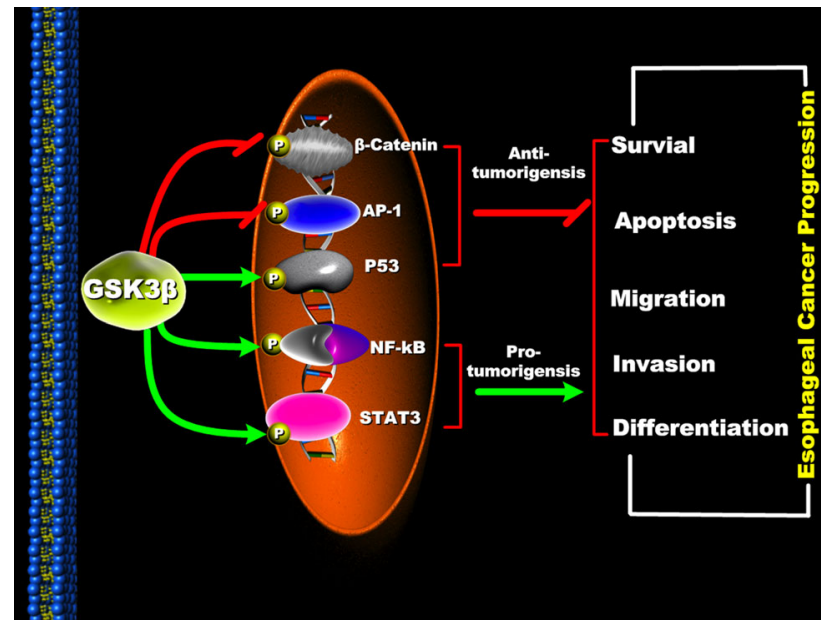

Fig. 3 The influence of GSK3 on transcription factors known to regulate cancer progression. GSK3 has been shown to promote the activation of $\mathrm{p} 53$, a known tumor suppressor. In addition, both AP-1 and $\beta$-catenin have been shown to promote EC progression. However, both are inhibited upon GSK3 activation, which may inhibit disease progression. Reciprocally, GSK3 may actually promote EC by facilitating the activation of NF- $\mathrm{KB}$ and STAT3, two transcription factors implicated in EC development. Further studies are needed to elicit the role of GSK3 $\beta$ in regulating these transcription factors in the context of EC tumorigenesis and disease progression

regulating the nature and magnitude of innate and adaptive immune response (Rehani et al. 2009; Wang et al. 2008, 2011c). In this regard, inhibition of GSK3 $\beta$

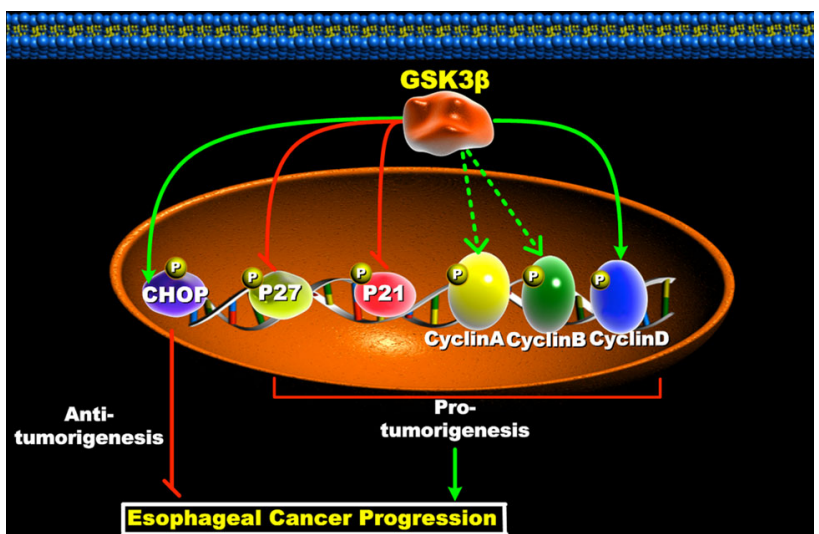

Fig. 4 GSK3 $\beta$ mediated the control of cell cycle progression. Cyclin D1, A, and B have been shown to be overexpressed in EC and contribute to disease progression. Expression of a constitutively active GSK3 has been shown to increase expression of cyclin D1 by preventing its degradation. While no direct evidence exists demonstrating that GSK3 regulates cyclin A or B, GSK3 has been shown to facilitate p53 and c-Myc activation, which have been shown to regulate cyclin A and $\mathrm{B}$. In addition, GSK3 activation also leads to the downregulation of both p21 and p27, both potent EC suppressors. Collectively, this would indicate that GSK3 promotes the cell cycle conditions that facilitate EC progression; however, it is currently unclear if GSK3 actually is a key regulator of any of these cell cycle proteins in the context of EC

was demonstrated to suppress innate immune responses by reducing the production of IL-1 $\beta$, IL-6, tumor necrosis factor (TNF), and IL-12 while concurrently enhancing the production of IL-10, IL-1 receptor antagonist (IL-1Ra), interferon (IFN)- $\beta$, and IFN- $\beta$ induced IL-10 in TLRs-stimulated cells (Rehani et al. 2009; Wang et al. 2008, 2011a). Moreover, many studies have also demonstrated the functional role of GSK3 in the adaptive immune responses. Welsh et al. (1996) reported that the activity of GSK3 was affected in mitogenstimulated human $\mathrm{T}$ cells. The role of GSK3 in regulating antigen-specific $\mathrm{CD}^{+} \mathrm{T}$ cells was subsequently reported by Ohteki et al. (2000) and showed that antigen-specific stimulation of $\mathrm{CD}^{+} \mathrm{T}$ cells resulted in the inactivation of GSK3, which enhanced IL-2 production and increased cellular proliferation. Other studies demonstrated that GSK3 was an important effector molecule involved in the B7-CD28 co-stimulatory signaling pathway. CD28 co-stimulation of $\mathrm{T}$ cells was shown to increase PI3K activity and mediate the inactivation of GSK3 (Pages et al. 1994; Wood et al. 2006). In addition, studies using the Leishmania major infection model have shown that GSK3 inhibition suppressed Th1 responses (Ohtani et al. 2008) on a systematic level. Taken together, these findings demonstrate that GSK3 plays a prominent role both in innate and adaptive immunity by regulating cytokine production and proliferation of $\mathrm{T}$ cells. 
Potential Influence of GSK3 $\beta$ on EC via Regulating Inflammatory Cytokine Production

Cytokines generated by activated immune cells are considered important components in orchestrating the relationship between inflammation and cancer. Studies conducted over the last several years have elucidated the molecular mechanism of intracellular signaling pathways of inflammatory cytokines, for example IL-6, TNF, IL-12, and IFN- $\gamma$ for tumor development (Kundu and Surh 2008; Masuhara et al. 1997). The involvement of cytokines in tumor development is mainly through activating a series of intracellular kinases, which subsequently leads to the activation of different TFs, such as nuclear factor (NF)- $\kappa B$, signal transducer and activator of transcription (STAT3), and activator protein (AP)-1. The ability of GSK3 $\beta$ inhibition to differentially regulate the production of pro- and anti-inflammatory cytokine production and its functional role in adaptive immune responses suggests that it might play an important role in the progression of EC (Fig. 2). We will, therefore, discuss the potential influences of GSK3 $\beta$ in the development of EC through its ability to regulate inflammatory cytokine expression.

\section{Il-12}

IL-12 has been demonstrated to enhance the generation and activation of cytotoxic lymphocytes, and the production of cytokines, especially IFN- $\gamma$ in T lymphocytes and NK cells (Ma et al. 1996). It has been shown that endogenous IL-12 is required not only for resistance to many pathogens but also for chemically induced tumors. Using experimental models, recombinant IL-12 was reported to have a dramatic anti-tumor effect on various tumors including esophageal cancer (Cardenes et al. 2010; Mu et al. 1995; Pham-Nguyen et al. 1999). Moreover, genetic defects in IL-12 production have been shown to predispose individuals to EC (Cardenes et al. 2010). IL-12 is believed to suppress tumor development by enhancing the production of IFN- $\gamma$, activating a potent anti-angiogenic response, or by having a direct toxic effect on tumor cells (Kito et al. 2003; Voest et al. 1995); however, IL-12 levels in serum increase with the progression of tumor invasion (Diakowska et al. 2006). In EC for example, the average level of IL-12 in the serum of esophageal cancer patients is significantly higher than that of healthy volunteers (Diakowska et al. 2006; Tsuboi et al. 2004). The survival rate of patients with EC who had high serum levels of IL-12 was significantly less than that of patients with low IL-12 levels (Tsuboi et al. 2004). Van Standick et al. (2003) analyzed the serum levels of IL-12 and IFN- $\gamma$ in different stages of EC and found that the preoperative immune response was able to predict the development of major infections after esophageal cancer surgery. It is unclear if elevated IL-12 facilitates EC disease severity or if it is simply a symptom since IL-12 is known to have anti-tumor effects. The inverse association of IL-12 levels in tissue and serum in the development and prognosis of EC suggests a complex mechanism behind this process. Active GSK3 $\beta$ has been shown to enhance the production of IL-12 upon IFN- $\gamma$ stimulation. Thus, activation of GSK3 $\beta$ might suppress the progression of EC by enhancing the production of IL-12 (Fig. 2).

\section{Tumor Necrosis Factor}

TNF treatment was reported to significantly reduce tumor response rates in immunodeficient mice, which suggested that the antitumor activity of TNF is, at least in part, mediated by the immune system (Eggermont et al. 2003). TNF has been demonstrated to induce the production of other cytokines (e.g. IL-1, IL-8) and cytotoxic factors (e.g. nitric oxide (NO), reactive oxygen species) by macrophages, which can mediate tumor suppression in mice (Vujanovic 2001). In contrast, TNF was also reported to possess tumor-promoting effects (Arnott et al. 2002). It has been shown that low doses of TNF can promote the proliferation of some malignant cell lines (Ferrajoli et al. 2002). Although the molecular details of such tumor-promoting activity are not clear, it is believed that TNF can affect the initiation or progression of cancer by a variety of mechanisms such as inducing DNA damage and inhibiting DNA repair by enhancing the production of genotoxic molecules (e.g. NO) in cancer cells or bystander cells (Dhar et al. 2002); enhancing expression of matrix metalloproteinases in malignant cells (Hanemaaijer et al. 1993); or driving the overexpression of various pro-cancer factors (e.g. E-selectin, IL-8, VEGF, $\beta$-FGF, ephrin-A, and ICAM-1) (Cheng and Chen 2001; De Cesaris et al. 1999; Yoshida et al. 1997). In the development of EC, TNF polymorphisms have been shown to be strongly associated with tumor development. For example, gene polymorphism of TNF is associated with an increased risk of EC development and might be a useful marker to predict the risk of EC (Menke et al. 2012). Using various human EC cell lines, Saito et al. (1994a) reported the significant antitumor effects of recombinant human TNF. Moreover, increased TNF was reported to enhance the radiosensitivity of EC patients by interacting with ionizing radiation and subsequently produced greater tumor regression and a delay in tumor regrowth (Gupta et al. 2003). In contrast to the antiEC effects of TNF, there are also several reports that have shown that TNF can promote EC via enhancing expression of oncogenes like c-Myc and $\beta$-catenin (Tselepis et al. 2002). These conflicting results about the function of TNF 
in EC suggest that further clinical investigation with a large number of patients or experiments using animal models should be performed to assess the therapeutic value of TNF. Most likely, the concentration and timing of TNF production during tumor development will drastically alter the properties of TNF as either pro- or anti-tumorigenesis. Our lab and others have demonstrated that GSK3 $\beta$ activity enhances the production of TNF in different cell types (Agarwal et al. 2013; Martin et al. 2005), which potentially makes GSK3-mediated regulation of TNF a factor in EC development (Fig. 2).

\section{Il-6}

Accumulating evidence demonstrates that IL- 6 is associated with the initiation and progression of various cancers including EC. IL-6 functions by binding the IL-6 receptor which activates a cytoplasmic tyrosine kinase bound to gp130 (Murakami et al. 1993). This leads to the activation of multiple signaling pathways involving MAPKs, PI3Ks, and STATs (Hirano et al. 1997). In light of the reported involvement of IL-6 and its downstream targets in the regulation of cell proliferation, survival, and metabolism, it is not surprising that IL-6 signaling has also been implicated in tumorigenesis (Hodge et al. 2005). In esophageal cancer, it has been reported that both IL-6 and IL-6R are expressed in tumor tissue (Leu et al. 2003). Moreover, tissue concentration of IL-6 was significantly higher in the tumor than in the normal epithelium (Oka et al. 1996a). Furthermore, studies by Oka et al. (1996b) demonstrated that esophageal squamous carcinoma cells (ESCC) simultaneously produced both IL-6 and IL-6R, which indicated that there might be an autocrine loop of IL- 6 and IL-6R involved in the progression of ESCC. Through the rapid phosphorylation of gp130 and STAT3, IL-6 has been shown to repress the apoptosis of ESCC (Leu et al. 2003). In addition, IL-6 has been shown to enhance the expression of vascular endothelial growth factor (VEGF), which has been shown to be essential for the development, growth, and progression of various tumors (Huang et al. 2002). Thus, IL-6 mediated angiogenesis could be another mechanism used to influence the progression of EC. Studies by Oka et al. (1996a)have shown that the serum levels of IL-6 are frequently elevated in patients with EC and are closely associated with a poor prognosis of survival. Collectively, these studies have demonstrated the protumorigenesis effect of IL- 6 and inhibition of GSK $3 \beta$ has been established as a strong IL-6 suppressor in different cell types (Grzesiak et al. 2005; Martin et al. 2005). GSK3 inhibition might be an important therapeutic approach, at least in terms of IL-6, to suppress the progression of EC by diminishing the levels of IL- 6 either in tumor tissue or serum.

\section{Il-17A}

IL-17A is a cytokine produced primarily by activated T cells including Th17 cells, NKT cells and $\gamma \delta \mathrm{T}$ cells (Harrington et al. 2005; Park et al. 2005; Yao et al. 1995). IL-17 can inhibit tumor growth by increasing the generation and activity of cytotoxic T lymphocytes (Benchetrit et al. 2002). Compared with wild-type controls, IL-17deficient mice were reported to display increased numbers of lung metastases and rapid tumor growth of MC38 colon adenocarcinoma (Kryczek et al. 2009). In the setting of therapy-induced inflammation, IL-17A signaling was demonstrated to be required for the generation of IFN- $\gamma$ secreting, tumor antigen specific $\mathrm{T}$ cell immunity during chemotherapy (Ma et al. 2011). The effectiveness of mounting this protective anti-tumor immunity depends on IL-17 production, mainly from $\gamma \delta \mathrm{T}$ cells. In contrast with the above mentioned antitumor effects, IL-17A was also observed to promote the progression of various tumors. Several studies showed that IL-17A is able to induce a wide range of angiogenic mediators, including VEGF and IL-8 (Honorati et al. 2006; Kehlen et al. 1999). In addition, the ability of IL-17A to induce IL-6 is another possible way to promote tumor growth through the IL-6 mediated, antiapoptotic pathway (Wang et al. 2009). In the blood and tumor tissue of EC patients, Th17 percentages and Th17related cytokines including IL-23, IL-6, and IL-1 $\beta$ was significantly increased (Chen et al. 2012a). Further studies have shown that there is a positive correlation between the levels of IL-17 producing cells and the densities of $\mathrm{CD}^{+} \mathrm{T}$ cells, as well as the CD57 ${ }^{+} \mathrm{T}$ cells in the tumor tissue of esophageal cancer. Prognosis analysis has shown that high levels of IL-17 producing cells correlate with improved survival in ESCC patients. Since production of IL-17 is promoted by GSK3 activity in different cell types (Beurel et al. 2010; Wang et al. 2011a), GSK3 could be involved in the prognosis and the progression of EC via its ability to enhance IL-17 production (Chen et al. 2012a; Lv et al. 2011) (Fig. 2).

\section{IL-1及}

IL-1 $\beta$ has been shown to act as a double-edged sword in the development of tumors. In the context of immunogenic chemotherapy, IL- $1 \beta$ is essential for the adequate polarization of IFN- $\gamma$-producing $\mathrm{CD}^{+} \mathrm{T}$ cells, production of IL-17, and the generation of anti-tumor $\gamma \delta \mathrm{T}$ cells (Ma et al. 2011; Mattarollo et al. 2011). In the absence of the IL-1 receptor 1 or in the presence of IL-1Ra, dying tumor cells fail to prime cancer specific IFN- $\gamma$ producing $\mathrm{CD}^{+} \mathrm{T}$ cells (Ghiringhelli et al. 2009). On the other hand, excessive IL-1 $\beta$ production has been implicated in chronic inflammatory 
diseases and malignancies (Dinarello 2011). IL-1 $\beta$ has been reported to be increased in a variety of tumors including pancreas, colon rectum, skin, fibrosarcomas, and B16 melanoma (Arlt et al. 2002; Krelin et al. 2007; Maihofner et al. 2003; Voronov et al. 2003), and contributes to tumor proliferation, metastasis, and resilience (Mukhopadhyay et al. 2006; Wolf et al. 2001). For esophageal squamous cell carcinoma, IL-1 $\beta$ was significantly overexpressed at both the mRNA and protein levels in the tumor tissue in patients (Chen et al. 2012b; Deans et al. 2006). Blockage of IL-1 $\beta$ is able to attenuate tumor growth, invasion ability, and treatment resistance of ESCC (Chen et al. 2012b). Moreover, IL-1 $\beta$ levels significantly correlated with higher clinical stages, lower response rates to concurrent chemoradiotherapy, and higher recurrence rates after curative treatment (Chen et al. 2012b). These results indicated that IL- $1 \beta$ is a significant predictive and prognostic molecular marker of EC and may be a promising molecular target for therapeutic intervention. However, as pointed out with IL-12, it is still unclear if elevated IL-1 levels are contributing to EC disease severity or are merely a sign of disease progression since it has been demonstrated that IL-1 has potent anti-tumor effects. Our studies (Martin et al. 2005; Rehani et al. 2009) identified the ability of GSK3 $\beta$ activation to enhance production of IL$1 \beta$ and suppress its antagonist IL-1Ra level indicating that GSK3 activation suppresses tumor progression through its ability to enhance IL-1 production (Fig. 2).

All these inflammatory cytokines can act to either promote tumor initiation or suppress tumor growth. These paradoxical phenomena might be explained by the types of cells making the cytokine, the stimuli that cell is receiving, and the time of production of these cytokines relative to tumor progression. The complex effect of cytokines on tumor growth and development suggests that more studies on the function and mechanisms of GSK3 will help unravel the effects of these cytokines and identify potent therapeutic targets to control various stages of cancer.

\section{GSK3ß-Mediated Control of Apoptosis and Its Implications in EC}

Apoptosis is a genetically controlled and evolutionarily conserved form of cell death that is of importance for normal embryonic development and for the maintenance of tissue homeostasis. Aberrant apoptosis is a major cause of neoplastic disorders and is an integral part of EC pathogenesis (Sugimura et al. 2012; Wang et al. 1998). Apoptosis is controlled either by extrinsic, receptor-mediated, or intrinsic, mitochondria-mediated, signaling pathways that are composed of a series of kinases (caspases) and cytosolic proteins like $\mathrm{Bcl}-2$ proteins ( $\mathrm{Li}$ et al.
1997; Ola et al. 2011). Bcl-2 proteins are a family comprised of over 20 members and are regarded as some of the key regulators of apoptosis. Higher levels of $\mathrm{Bcl}-2$ and lower levels of Bax are frequently reported in EC (Chatzopoulos et al. 2007; Kang et al. 2007; Sarbia et al. 1996, 1997). A recent report showed that slight changes in the activation of GSK3 $\beta$ could affect the expression of Bcl-2 (Suzuki et al. 2009). Therefore, it is no surprise that inhibition of GSK3 was reported to suppress the development of cancers. Ghosh and Altieri (2005) reported that GSK3 ablation resulted in P53-dependent apoptosis, which suppresses the growth of colorectal cancer in mice. Further studies demonstrated that inhibition of GSK3 $\beta$ suppressed the production of Bcl-2, which enhanced apoptosis in different cancerous cells (Ban et al. 2010; Ougolkov et al. 2007). Studies by Tan et al. (2005) demonstrated that pharmacological-mediated inhibition of GSK3 $\beta$ was shown to enhance apoptosis by increasing p53-dependent activation of Bax, leading to cytochrome c release, loss of mitochondrial membrane potential, and caspase- 9 processing. These studies strongly indicate that inhibition of GSK3 $\beta$ might be an effective therapeutic agent against the development of EC via employing different mechanisms to augment apoptosis. On the other hand, phospho-inactivation of GSK3 $\beta$ has been shown to boost the production of Bcl-2 by enhancing the activity of CREB-ATF-1 in the context of t-Darpp-mediated PI3K-Akt activation (Belkhiri et al. 2008) (t-Darpp: truncated isoform of dopamine and cyclic-AMP-regualted phosphoprotein of $\mathrm{Mr} 32,000$ ). Other studies confirm this phenomenon by providing quantitative evidence that phosphorylation of Akt and subsequent inactivation of its substrate GSK $3 \beta$ are capable of suppressing apoptosis in invasive prostate cancer (Paweletz et al. 2001). All these lines of evidence unveiled the complexity of GSK3 $\beta$ influences on cell apoptosis and cancer progression.

\section{GSK3ß Affects Tumorigenesis of EC through Transcription Factor Modification (AP-1, NF-кB, c-Myc, $\beta$-Catenin, P53, STATs)}

Alternation of activity and/or expression of TFs plays different roles in tumorigenesis at different stages by altering the transcriptional machinery that regulates mRNA synthesis. Based on published literature, GSK3 $\beta$ regulates the stability of various oncogenic TFs such as the AP-1, NF- $\kappa B$, c-Myc, $\beta$-catenin, P53, and STATs (Fig. 3). Most of these TFs have been reported as physiological targets of GSK3 $\beta$ that undergo proteasomal degradation upon phosphorylation. Thus, summarizing the function of these TFs in the development of EC and the regulatory influence of GSK3 $\beta$ would direct us toward understanding the potential 
of GSK3 3 as a molecular target of EC and other cancers. AP-1, a dimeric transcription factor that is comprised of c-Jun and c-Fos, was shown to highly express in EC and was closely associated with the development of EC (Hussain et al. 2009; Jimeno et al. 2006). c-Jun has been reported to play a critical role in carcinogenesis and cell apoptosis via emigrating from the cytoplasm to the nucleus (Taira et al. 2012; Wang et al. 2011d). GSK3 $\beta$ is able to directly phosphorylate c-Jun at Thr 239 and then promote its degradation (Wei et al. 2005), which highlights another possible role for GSK3 in EC progression.

Activation of $\mathrm{NF}-\kappa \mathrm{B}$ promotes transcription of a wide variety of genes, which are related to inflammation and tumor growth (Baud and Karin 2009). Many studies have shown that NF- $\kappa \mathrm{B}$ plays a crucial role in the pathogenesis of esophageal adenocarcinoma (Abdel-Latif et al. 2004; Konturek et al. 2004; O'Riordan et al. 2005). NF- $\kappa \mathrm{B}$ is highly activated in EC samples (Abdel-Latif et al. 2004; O'Riordan et al. 2005). Moreover, the expression of NF- $\kappa \mathrm{B}$ in EC samples also correlated with the stage of the disease (Abdel-Latif et al. 2009). The activation of NF- $\kappa \mathrm{B}$ in both inflammation and the carcinogenesis of EC suggests that the $N F-\kappa B$ pathway may play a mechanistic role in the survival pathway of tumor cells. GSK3 $\beta$ has been shown to phosphorylate p65 at Ser468 and negatively regulate its activity by promoting its degradation (Buss et al. 2004). Recent reports suggest that active GSK3 $\beta$ physically interacts with $\mathrm{I} \kappa \mathrm{B} \alpha$ in normal epithelial cells (Ma et al. 2009) and then blocks NF- $\kappa \mathrm{B}$-dependent transcription by preventing $\mathrm{I} \kappa \mathrm{B} \alpha$ degradation (Sanchez et al. 2003). In contrast, our recent studies have demonstrated that inactivation of GSK3 suppressed the transcription of NF- $\mathrm{NB}$ mediated inflammatory cytokine production by decreasing the amount of cAMP response element-binding protein (CREB)-binding protein available to NF- $\kappa \mathrm{B}$ (Wang et al. 2011b). Two other reports confirmed our results by showing that increased levels of $\beta$-catenin mediated by GSK3 $\beta$ inhibition can antagonize NF- $\kappa \mathrm{B}$ activity (Deng et al. 2002). These conflicting results concerning the influence of GSK3 on NF- $\kappa \mathrm{B}$ activation may be the result of different cell types used in the experiments. These studies indicate that GSK3 $\beta$ might control the progression of EC by modifying the activation of $N F-\kappa B$ in different stages of tumorigenesis. Numerous studies reported that phospho-inactivation of GSK3 $\beta$ results in the degradation of c-Myc and $\beta$-catenin (Cadigan and Liu 2006; Yada et al. 2004). $\beta$-Catenin is a critical component of adherent junction in stratified squamous epithelium of esophageal. In normal epithelium, $\beta$-catenin is phosphorylated by GSK3 $\beta$ and then is degraded via ubiquitin-dependent proteasomes. However, when unphosphorylated, $\beta$-catenin accumulates in the cytoplasm and moves into the nucleus, which could lead to transcriptional activation of several oncogenes and promote cancer (Niessen and Gottardi 2008). Overexpression of $\beta$-catenin has been shown in the nucleus of EC cells, which indicates GSK3 $\beta$ inhibition could promote the development of EC via regulating degradation and localization of $\beta$-catenin (Veeramachaneni et al. 2004; Zhou et al. 2002).

P53 plays an important role in the regulation of apoptosis and cell growth. Loss of P53 activity is associated with uncontrolled cell cycle progression and tumor formation (Halm et al. 2000). As a known tumor suppressor, p53 gene polymorphisms and its expression have been closely associated with the development and severity of EC (Wang et al. 1998, 2003). Several studies have reported that GSK3 $\beta$ promotes the activation of p53 either by physical association or phosphorylation and post-translational modification (Eom and Jope 2009; Watcharasit et al. 2003), which suggest that active GSK3 $\beta$ might be able to repress tumorigenesis and the development of EC by enhancing the activity of p53.

Finally, STAT3 is a key transcription factor involved in the inflammatory response, as well as in cell proliferation, differentiation, and cell survival (Brierley and Fish 2005). It has been reported that increased activity of STAT3, either by inflammatory cytokines or other extracellular stimuli, participated in the tumorigenesis of EC (Leu et al. 2003; Yan et al. 2008). Further studies have shown that inhibition of STAT3 activity suppressed the development of EC by enhancing cell apoptosis and cell cycle arrest (Turkson 2004). Recent studies by Dr. Jope showed that activation of STAT3 is highly dependent on GSK3 and inhibition of GSK reduced the tyrosine phosphorylation of STAT3 (Beurel and Jope 2008). Moreover, they observed that regulation of GSK3 on the STATs is selective: only STAT3 and STAT5 are activated by GSK3, not STAT1 and STAT6 (Beurel and Jope 2008). Another finding by Moh et al. (2008) reported that STAT3 was able to regulate GSK3 $\beta$ levels in response to insulin, which indicated a possible positive feedback loop between GSK3 $\beta$ and STAT3 activation. The selectivity of GSK3 in STAT phosphorylation indicates more studies on the underlying mechanisms are needed to understand the function of GSK3 $\beta$ and its role in the development of EC in regard to STAT regulation (Fig. 3).

All of the above TFs or signaling molecules are involved in the development of esophageal cancer and are directly regulated by GSK3 $\beta$, indicating the importance of GSK3 $\beta$ in EC biology and the potential it possesses as a molecular target in EC treatment. However, as indicated, GSK3 activity may either promote activation of pro-EC factors, such as NF- $\kappa \mathrm{B}$ and STAT3, or promote activation of antiEC factors, such as p53. The timing of GSK3 activation during tumorigenesis and EC stages may explain this contradictory role GSK3 appears to play in this disease. 
However, due to the limited reports on the expression and activation of GSK3 $\beta$ in EC, more studies on GSK3 $\beta$ expression profiles in different stages and histotypes of EC will be very helpful in establishing the relationship between GSK3 $\beta$ and the development of EC.

\section{GSK3 $\beta$ Affects Tumorigenesis of EC via Regulating Cell Cycle}

Cell cycle is a series of events that takes place in a cell leading to its division and replication. Three key classes of regulatory molecules, cyclins, cyclin-dependent kinase (CDKs), and CDK inhibitors (CDKI) determine a cell's progress through cell cycle. Overexpression of cyclin D1 and cyclin $\mathrm{E}$ has been observed in esophageal cancer cell lines and tumor tissues (Jiang et al. 1992; Matsumoto et al. 1999; Wang et al. 1996). Further studies have reported that upregulation of cyclin D1/E in EC is achieved by regulating TFs such as $\mathrm{AP}-1, \mathrm{NF}-\kappa \mathrm{B}$, and $\beta$-catenin, which leads to the accumulation of the cyclins in the nucleus of cell (Arber et al. 1999; Verde et al. 2007) (Fig. 4).

Incremental evidence has shown that overexpressing a constitutively active form of GSK $3 \beta$ increased cyclin D1 expression, induced cell entry into the $S$ phase, and facilitated the proliferation of cancer (Cao et al. 2006; Mai et al. 2009). Since GSK3 activation prevents the degradation of cyclin D1, it stands to reason that inhibition of GSK3 might be an effective way to diminish cyclin D1 levels and inhibit EC progression. In additional to cyclin D and cyclin E, cyclin A and B are also overexpressed in human esophageal cancer (Furihata et al. 1996; Murakami et al. 1999). Although there is no evidence demonstrating that GSK3 directly regulates expression of cyclin $\mathrm{A}$ and $\mathrm{B}$, these cyclins are primarily regulated by c-Myc and P53, which potentially identifies them as downstream GSK3 $\beta$ targets.

As a known CDK inhibitor, P21 (WAF1/CIP1) competitively binds with CDKs. Decreased expression of P21 enhances cell cycle progression in the presence of DNA damage. The expression of P21 has been reported to be significantly decreased in various cancers (Maritz et al. 2011; Verbeke et al. 2010). In esophageal cancer, $\mathrm{Ku}-$ wahara et al. (1999) reported that there is a close association between P21 expression and the five-year survival rate of patients. The P21-positive group had a five-year survival rate of $50 \%$ compared to the $13.4 \%$ survival rate of the $\mathrm{P} 21$-negative group, which suggested that P21 is a good prognostic indicator for EC (Kuwahara et al. 1999). Moreover, expression and polymorphisms of P21 are closely related with therapeutic outcomes (Bahl et al. 2000; Nakamura et al. 2004). Overexpression of GSK3 $\beta$ has been shown to directly downregulate P21 expression by phosphorylation at Thr57, leading to proteasome-mediated degradation, whereas inhibition of GSK3 with lithium chloride interfered with P21 degradation and increased P21 protein levels about ten-fold in EC (Rossig et al. 2002). This finding indicates that inhibition of GSK3 might be a potential therapeutic approach for EC in the context of P21 expression (Fig. 4).

Another CDKI, P27, showed the same effect on the development of esophageal cancer as P21. Overexpression of P27 has been reported to inhibit the growth and multiplication of esophageal cancer cells and induce apoptosis (Tong et al. 2011; Wu et al. 2003). Moreover, using murine models with P27 knockout, Dr. Ellis found that P27 knockout mice were more likely to develop esophageal cancer (Ellis et al. 2001). The expression of P27 has been reportedly regulated by forkhead $\mathrm{O}$ family $\mathrm{TFs}$, which is modulated by the PI3K/GSK3 pathway (Ho et al. 2012; Nakao et al. 2008). A discovery by our laboratory showed the direct suppressive effect of GSK3 $\beta$ inhibition on P27kip1 expression (Garcia et al. 2008) (Fig. 4). Collectively, these data indicate that GSK3 inhibition may also increase P27 expression and improve prognosis outcomes in EC. In addition, CHOP/GADD153 (C/EBP-homologous protein) is an established apoptotic protein and tumor suppressor involved in multiple tumor types but so far, has not been studied in esophageal cancer. It has been shown that inhibition of GSK3 effectively reduced the expression of CHOP and enhanced cell survival (Meares et al. 2011) (Fig. 4). Thus, GSK3 inhibition may play different roles in the progression of EC in the context of different proteins. More studies on the expression profile of CHOP/GADD153 in all stages of EC and the regulatory effect of GSK3 $\beta$ on CHOP/GADD153 will be very helpful in understanding the development of EC.

GSK3 $\beta$ has dual functions in the progression of different types of cancer. Phospho-inactivation of GSK3 $\beta$ has been reported in most cancers but so far, not in EC samples. Our unpublished data have also shown that the expression of phosphorylated GSK3 is significantly higher in the tumor tissue of EC than normal tissue. However, other studies indicate that GSK3 $\beta$ is overexpressed in many human malignancies that may offset the observed phospho-inactivation (Ougolkov et al. 2006; Shakoori et al. 2005). Future work should aim at determining the role of GSK3 in an in vivo setting, under the pressures of the host immune response, and during various stages of the disease since GSK3 activity, like many proteins, could shift drastically during disease progression. Thus, determining the expression profile of GSK3 $\beta$ in different histotypes of ECs and deciphering the underlying signaling events involved can clarify the function of GSK3 $\beta$ in the development of EC and also highlight potential therapeutic applications. 


\section{Conclusion}

Exploring the cell biology of EC reveals a complicated molecular signaling network, including numerous TFs and various inflammatory mediators controlling the initiation and development of EC. Due to the limited knowledge on the underlying mechanisms of EC regulators and their relationship with GSK3, continued work on the signaling pathways involved in tumorigenesis will be beneficial in the diagnostic and therapeutic approaches to the disease. The regulatory effects of GSK3 $\beta$ on various TFs, inflammatory cytokines, apoptosis, and cell cycle, have strong implications in the development, treatment, and projected outcomes of esophageal cancer.

\section{References}

Abdel-Latif MM, O'Riordan J, Windle HJ et al (2004) NF-kappaB activation in esophageal adenocarcinoma: relationship to Barrett's metaplasia, survival, and response to neoadjuvant chemoradiotherapy. Ann Surg 239:491-500

Abdel-Latif MM, Kelleher D, Reynolds JV (2009) Potential role of NF-kappaB in esophageal adenocarcinoma: as an emerging molecular target. J Surg Res 153:172-180

Agarwal D, Dange RB, Raizada MK et al (2013) Angiotensin II causes imbalance between pro- and anti-inflammatory cytokines by modulating GSK-3beta in neuronal culture. Br J Pharmacol 169:860-874

Ali A, Hoeflich KP, Woodgett JR (2001) Glycogen synthase kinase-3: properties, functions, and regulation. Chem Rev 101:2527-2540

Arber N, Gammon MD, Hibshoosh H et al (1999) Overexpression of cyclin D1 occurs in both squamous carcinomas and adenocarcinomas of the esophagus and in adenocarcinomas of the stomach. Hum Pathol 30:1087-1092

Arlt A, Vorndamm J, Muerkoster S et al (2002) Autocrine production of interleukin 1beta confers constitutive nuclear factor kappaB activity and chemoresistance in pancreatic carcinoma cell lines. Cancer Res 62:910-916

Arnott CH, Scott KA, Moore RJ et al (2002) Tumour necrosis factoralpha mediates tumour promotion via a PKC alpha- and AP-1dependent pathway. Oncogene 21:4728-4738

Bahl R, Arora S, Nath N et al (2000) Novel polymorphism in p21(waf1/cip1) cyclin dependent kinase inhibitor gene: association with human esophageal cancer. Oncogene 19:323-328

Balkwill F, Mantovani A (2001) Inflammation and cancer: back to Virchow? Lancet 357:539-545

Ban JO, Kwak DH, Oh JH et al (2010) Suppression of NF-kappaB and GSK-3beta is involved in colon cancer cell growth inhibition by the PPAR agonist troglitazone. Chem Biol Interact 188:75-85

Baud V, Karin M (2009) Is NF-kappaB a good target for cancer therapy? Hopes and pitfalls. Nat Rev Drug Discov 8:33-40

Belkhiri A, Dar AA, Zaika A et al (2008) t-Darpp promotes cancer cell survival by up-regulation of Bcl2 through Akt-dependent mechanism. Cancer Res 68:395-403

Benchetrit F, Ciree A, Vives V et al (2002) Interleukin-17 inhibits tumor cell growth by means of a T-cell-dependent mechanism. Blood 99:2114-2121

Beurel E, Jope RS (2008) Differential regulation of STAT family members by glycogen synthase kinase-3. J Biol Chem 283:21934-21944
Beurel E, Yeh WI, Michalek SM et al (2010) Glycogen synthase kinase- 3 is an early determinant in the differentiation of pathogenic Th17 cells. J Immunol 186:1391-1398

Blot WJ, Devesa SS, Kneller RW et al (1991) Rising incidence of adenocarcinoma of the esophagus and gastric cardia. JAMA 265:1287-1289

Bornschein J, Selgrad M, Warnecke M et al (2010) H. pylori infection is a key risk factor for proximal gastric cancer. Dig Dis Sci $55: 3124-3131$

Brady MJ, Bourbonais FJ, Saltiel AR (1998) The activation of glycogen synthase by insulin switches from kinase inhibition to phosphatase activation during adipogenesis in 3T3-L1 cells. J Biol Chem 273:14063-14066

Brierley MM, Fish EN (2005) Stats: multifaceted regulators of transcription. J Interferon Cytokine Res 25:733-744

Buss H, Dorrie A, Schmitz ML et al (2004) Phosphorylation of serine 468 by GSK-3beta negatively regulates basal p65 NF-kappaB activity. J Biol Chem 279:49571-49574

Cadigan KM, Liu YI (2006) Wnt signaling: complexity at the surface. J Cell Sci 119:395-402

Cao Q, Lu X, Feng YJ (2006) Glycogen synthase kinase-3beta positively regulates the proliferation of human ovarian cancer cells. Cell Res 16:671-677

Cardenes M, Angel-Moreno A, Fieschi C et al (2010) Oesophageal squamous cell carcinoma in a young adult with IL-12R beta 1 deficiency. J Med Genet 47:635-637

Chatzopoulos D, Kyrgidis A, Kountouras J et al (2007) Bax upregulation may provide a rationale for the low incidence of esophageal adenocarcinoma in a Greek cohort of patients with Barrett's esophagus. Hepatogastroenterology 54:705-709

Chen D, Hu Q, Mao C et al (2012a) Increased IL-17-producing CD4(+) $\mathrm{T}$ cells in patients with esophageal cancer. Cell Immunol 272:166-174

Chen MF, Lu MS, Chen PT et al (2012b) Role of interleukin 1 beta in esophageal squamous cell carcinoma. J Mol Med 90:89-100

Cheng N, Chen J (2001) Tumor necrosis factor-alpha induction of endothelial ephrin A1 expression is mediated by a p38 MAPKand SAPK/JNK-dependent but nuclear factor-kappa B-independent mechanism. J Biol Chem 276:13771-13777

Coleman MP, Gatta G, Verdecchia A et al (2003) EUROCARE-3 summary: cancer survival in Europe at the end of the 20th century. Ann Oncol 14(Suppl 5):v128-v149

Colotta F, Allavena P, Sica A et al (2009) Cancer-related inflammation, the seventh hallmark of cancer: links to genetic instability. Carcinogenesis 30:1073-1081

Crew KD, Neugut AI (2004) Epidemiology of upper gastrointestinal malignancies. Semin Oncol 31:450-464

Cross DA, Alessi DR, Vandenheede JR et al (1994) The inhibition of glycogen synthase kinase-3 by insulin or insulin-like growth factor 1 in the rat skeletal muscle cell line L6 is blocked by wortmannin, but not by rapamycin: evidence that wortmannin blocks activation of the mitogen-activated protein kinase pathway in L6 cells between Ras and Raf. Biochem J 303(Pt 1):21-26

De Cesaris P, Starace D, Starace G et al (1999) Activation of Jun $\mathrm{N}$-terminal kinase/stress-activated protein kinase pathway by tumor necrosis factor alpha leads to intercellular adhesion molecule-1 expression. J Biol Chem 274:28978-28982

Deans DA, Wigmore SJ, Gilmour H et al (2006) Elevated tumour interleukin-1beta is associated with systemic inflammation: a marker of reduced survival in gastro-oesophageal cancer. $\mathrm{Br} \mathrm{J}$ Cancer 95:1568-1575

Deng J, Miller SA, Wang HY et al (2002) beta-catenin interacts with and inhibits NF-kappa B in human colon and breast cancer. Cancer Cell 2:323-334 
Dhar A, Young MR, Colburn NH (2002) The role of AP-1, NFkappaB and ROS/NOS in skin carcinogenesis: the JB6 model is predictive. Mol Cell Biochem 234-235:185-193

Diakowska D, Markocka-Maczka K, Grabowski K et al (2006) Serum interleukin-12 and interleukin-18 levels in patients with oesophageal squamous cell carcinoma. Exp Oncol 28:319-322

Dinarello CA (2011) A clinical perspective of IL-1beta as the gatekeeper of inflammation. Eur J Immunol 41:1203-1217

Doble BW, Woodgett JR (2003) GSK-3: tricks of the trade for a multi-tasking kinase. J Cell Sci 116:1175-1186

Eggermont AM, de Wilt JH, ten Hagen TL (2003) Current uses of isolated limb perfusion in the clinic and a model system for new strategies. Lancet Oncol 4:429-437

Ellis FH Jr, Xu X, Kulke MH et al (2001) Malignant transformation of the esophageal mucosa is enhanced in p27 knockout mice. J Thorac Cardiovasc Surg 122:809-814

Embi N, Rylatt DB, Cohen P (1980) Glycogen synthase kinase-3 from rabbit skeletal muscle. Separation from cyclic-AMP-dependent protein kinase and phosphorylase kinase. Eur $\mathrm{J}$ Biochem 107:519-527

Eom TY, Jope RS (2009) GSK3 beta N-terminus binding to p53 promotes its acetylation. Mol Cancer 8:14

Ernst PB, Gold BD (2000) The disease spectrum of Helicobacter pylori: the immunopathogenesis of gastroduodenal ulcer and gastric cancer. Annu Rev Microbiol 54:615-640

Eslick GD (2010) Infectious causes of esophageal cancer. Infect Dis Clin North Am 24:845-852, vii

Fang X, Yu S, Tanyi JL et al (2002) Convergence of multiple signaling cascades at glycogen synthase kinase 3: Edg receptormediated phosphorylation and inactivation by lysophosphatidic acid through a protein kinase C-dependent intracellular pathway. Mol Cell Biol 22:2099-2110

Ferrajoli A, Keating MJ, Manshouri T et al (2002) The clinical significance of tumor necrosis factor-alpha plasma level in patients having chronic lymphocytic leukemia. Blood 100:1215-1219

Fiol CJ, Mahrenholz AM, Wang Y et al (1987) Formation of protein kinase recognition sites by covalent modification of the substrate. Molecular mechanism for the synergistic action of casein kinase II and glycogen synthase kinase 3. J Biol Chem 262:14042-14048

Fitzgerald RC, Abdalla S, Onwuegbusi BA et al (2002a) Inflammatory gradient in Barrett's oesophagus: implications for disease complications. Gut 51:316-322

Fitzgerald RC, Onwuegbusi BA, Bajaj-Elliott M et al (2002b) Diversity in the oesophageal phenotypic response to gastrooesophageal reflux: immunological determinants. Gut 50:451-459

Frame S, Cohen P, Biondi RM (2001) A common phosphate binding site explains the unique substrate specificity of GSK3 and its inactivation by phosphorylation. Mol Cell 7:1321-1327

Furihata M, Ishikawa T, Inoue A et al (1996) Determination of the prognostic significance of unscheduled cyclin A overexpression in patients with esophageal squamous cell carcinoma. Clin Cancer Res 2:1781-1785

Garcea G, Manson MM, Neal CP et al (2007) Glycogen synthase kinase-3 beta; a new target in pancreatic cancer? Curr Cancer Drug Targets 7:209-215

Garcia CA, Benakanakere MR, Alard P et al (2008) Antigenic experience dictates functional role of glycogen synthase kinase-3 in human CD4+ T cell responses. J Immunol 181:8363-8371

Garcia CA, Wang H, Benakanakere MR et al (2009) c-jun controls the ability of IL-12 to induce IL-10 production from human memory CD4+ T cells. J Immunol 183:4475-4482

Ghiringhelli F, Apetoh L, Tesniere A et al (2009) Activation of the NLRP3 inflammasome in dendritic cells induces IL-1beta- dependent adaptive immunity against tumors. Nat Med 15:1170-1178

Ghosh JC, Altieri DC (2005) Activation of p53-dependent apoptosis by acute ablation of glycogen synthase kinase-3beta in colorectal cancer cells. Clin Cancer Res 11:4580-4588

Grivennikov SI, Greten FR, Karin M (2010) Immunity, inflammation, and cancer. Cell 140:883-899

Grzesiak JJ, Smith KC, Chalberg C et al (2005) Type I collagen and divalent cation shifts disrupt cell-cell adhesion, increase migration, and decrease PTHrP, IL-6, and IL-8 expression in pancreatic cancer cells. Int J Gastrointest Cancer 36:131-146

Gupta VK, Park JO, Kurihara T et al (2003) Selective gene expression using a DF3/MUC1 promoter in a human esophageal adenocarcinoma model. Gene Ther 10:206-212

Halm U, Tannapfel A, Breitung B et al (2000) Apoptosis and cell proliferation in the metaplasia-dysplasia-carcinoma-sequence of Barrett's esophagus. Hepatogastroenterology 47:962-966

Hanemaaijer R, Koolwijk P, le Clercq L et al (1993) Regulation of matrix metalloproteinase expression in human vein and microvascular endothelial cells. Effects of tumour necrosis factor alpha, interleukin 1 and phorbol ester. Biochem J 296 (Pt 3):803-809

Harrington LE, Hatton RD, Mangan PR et al (2005) Interleukin 17-producing $\mathrm{CD} 4+$ effector $\mathrm{T}$ cells develop via a lineage distinct from the $\mathrm{T}$ helper type 1 and 2 lineages. Nat Immunol 6:1123-1132

Hirano T, Nakajima K, Hibi M (1997) Signaling mechanisms through gp130: a model of the cytokine system. Cytokine Growth Factor Rev 8:241-252

Ho WC, Pikor L, Gao Y et al (2012) Calpain 2 regulates Akt-FoxOp27(Kip1) protein signaling pathway in mammary carcinoma. J Biol Chem 287:15458-15465

Hodge DR, Hurt EM, Farrar WL (2005) The role of IL-6 and STAT3 in inflammation and cancer. Eur J Cancer 41:2502-2512

Honorati MC, Neri S, Cattini L et al (2006) Interleukin-17, a regulator of angiogenic factor release by synovial fibroblasts. Osteoarthritis Cartilage 14:345-352

Huang SP, Wu MS, Wang HP et al (2002) Correlation between serum levels of interleukin- 6 and vascular endothelial growth factor in gastric carcinoma. J Gastroenterol Hepatol 17:1165-1169

Hussain SP, Harris CC (2007) Inflammation and cancer: an ancient link with novel potentials. Int J Cancer 121:2373-2380

Hussain S, Bharti AC, Salam I et al (2009) Transcription factor AP-1 in esophageal squamous cell carcinoma: alterations in activity and expression during human Papillomavirus infection. BMC Cancer 9:329

Itzkowitz SH, Yio X (2004) Inflammation and cancer IV. Colorectal cancer in inflammatory bowel disease: the role of inflammation. Am J Physiol Gastrointest Liver Physiol 287:G7-G17

Jiang W, Kahn SM, Tomita N et al (1992) Amplification and expression of the human cyclin D gene in esophageal cancer. Cancer Res 52:2980-2983

Jimeno A, Kulesza P, Kincaid E et al (2006) C-fos assessment as a marker of anti-epidermal growth factor receptor effect. Cancer Res 66:2385-2390

Jope RS, Johnson GV (2004) The glamour and gloom of glycogen synthase kinase-3. Trends Biochem Sci 29:95-102

Jope RS, Yuskaitis CJ, Beurel E (2007) Glycogen synthase kinase-3 (GSK3): inflammation, diseases, and therapeutics. Neurochem Res 32:577-595

Kang SY, Han JH, Lee KJ et al (2007) Low expression of Bax predicts poor prognosis in patients with locally advanced esophageal cancer treated with definitive chemoradiotherapy. Clin Cancer Res 13:4146-4153

Kang T, Wei Y, Honaker Y et al (2008) GSK-3 beta targets Cdc25A for ubiquitin-mediated proteolysis, and GSK-3 beta inactivation 
correlates with Cdc25A overproduction in human cancers. Cancer Cell 13:36-47

Kehlen A, Thiele K, Riemann D et al (1999) Interleukin-17 stimulates the expression of IkappaB alpha mRNA and the secretion of IL-6 and IL-8 in glioblastoma cell lines. J Neuroimmunol 101:1-6

Kito T, Kuroda E, Yokota A et al (2003) Cytotoxicity in glioma cells due to interleukin-12 and interleukin-18-stimulated macrophages mediated by interferon-gamma-regulated nitric oxide. J Neurosurg 98:385-392

Kockeritz L, Doble B, Patel S et al (2006) Glycogen synthase kinase3 -an overview of an over-achieving protein kinase. Curr Drug Targets 7:1377-1388

Konturek PC, Nikiforuk A, Kania J et al (2004) Activation of NFkappaB represents the central event in the neoplastic progression associated with Barrett's esophagus: a possible link to the inflammation and overexpression of COX-2, PPARgamma and growth factors. Dig Dis Sci 49:1075-1083

Krelin Y, Voronov E, Dotan S et al (2007) Interleukin-1beta-driven inflammation promotes the development and invasiveness of chemical carcinogen-induced tumors. Cancer Res 67:1062-1071

Kryczek I, Wei S, Szeliga W et al (2009) Endogenous IL-17 contributes to reduced tumor growth and metastasis. Blood 114:357-359

Kundu JK, Surh YJ (2008) Inflammation: gearing the journey to cancer. Mutat Res 659:15-30

Kuwahara M, Hirai T, Yoshida K et al (1999) p53, p21(Waf1/Cip1) and cyclin D1 protein expression and prognosis in esophageal cancer. Dis Esophagus 12:116-119

Leu CM, Wong FH, Chang C et al (2003) Interleukin-6 acts as an antiapoptotic factor in human esophageal carcinoma cells through the activation of both STAT3 and mitogen-activated protein kinase pathways. Oncogene 22:7809-7818

Li P, Nijhawan D, Budihardjo I et al (1997) Cytochrome c and dATPdependent formation of Apaf-1/caspase-9 complex initiates an apoptotic protease cascade. Cell 91:479-489

Li N, Grivennikov SI, Karin M (2011) The unholy trinity: inflammation, cytokines, and STAT3 shape the cancer microenvironment. Cancer Cell 19:429-431

Lv L, Pan K, Li XD et al (2011) The accumulation and prognosis value of tumor infiltrating IL-17 producing cells in esophageal squamous cell carcinoma. PLoS ONE 6:e18219

Ma X, Chow JM, Gri G et al (1996) The interleukin 12 p40 gene promoter is primed by interferon gamma in monocytic cells. J Exp Med 183:147-157

Ma Y, Wang M, Li N et al (2009) Bleomycin-induced nuclear factorkappaB activation in human bronchial epithelial cells involves the phosphorylation of glycogen synthase kinase 3beta. Toxicol Lett 187:194-200

Ma Y, Aymeric L, Locher C et al (2011) Contribution of IL-17producing gamma delta $\mathrm{T}$ cells to the efficacy of anticancer chemotherapy. J Exp Med 208:491-503

Mai W, Kawakami K, Shakoori A et al (2009) Deregulated GSK3 beta\} sustains gastrointestinal cancer cells survival by modulating human telomerase reverse transcriptase and telomerase. Clin Cancer Res 15:6810-6819

Maihofner C, Charalambous MP, Bhambra U et al (2003) Expression of cyclooxygenase- 2 parallels expression of interleukin-1beta, interleukin-6 and NF-kappaB in human colorectal cancer. Carcinogenesis 24:665-671

Maritz MF, van der Watt PJ, Holderness N et al (2011) Inhibition of AP-1 suppresses cervical cancer cell proliferation and is associated with p21 expression. Biol Chem 392:439-448

Martin M, Rehani K, Jope RS et al (2005) Toll-like receptor-mediated cytokine production is differentially regulated by glycogen synthase kinase 3. Nat Immunol 6:777-784
Masuhara M, Sakamoto H, Matsumoto A et al (1997) Cloning and characterization of novel CIS family genes. Biochem Biophys Res Commun 239:439-446

Matsumoto M, Furihata M, Ishikawa T et al (1999) Comparison of deregulated expression of cyclin D1 and cyclin E with that of cyclin-dependent kinase 4 (CDK4) and CDK2 in human oesophageal squamous cell carcinoma. Br J Cancer 80:256-261

Mattarollo SR, Loi S, Duret H et al (2011) Pivotal role of innate and adaptive immunity in anthracycline chemotherapy of established tumors. Cancer Res 71:4809-4820

Meares GP, Mines MA, Beurel E et al (2011) Glycogen synthase kinase-3 regulates endoplasmic reticulum (ER) stress-induced CHOP expression in neuronal cells. Exp Cell Res 317:1621-1628

Menke V, van Zoest KP, Moons LM et al (2012) NcoI TNF-beta gene polymorphism and TNF expression are associated with an increased risk of developing Barrett's esophagus and esophageal adenocarcinoma. Scand J Gastroenterol 47:378-386

Moh A, Zhang W, Yu S et al (2008) STAT3 sensitizes insulin signaling by negatively regulating glycogen synthase kinase-3 beta. Diabetes 57:1227-1235

Moons LM, Kusters JG, van Delft JH et al (2008) A pro-inflammatory genotype predisposes to Barrett's esophagus. Carcinogenesis 29:926-931

$\mathrm{Mu}$ J, Zou JP, Yamamoto $\mathrm{N}$ et al (1995) Administration of recombinant interleukin 12 prevents outgrowth of tumor cells metastasizing spontaneously to lung and lymph nodes. Cancer Res 55:4404-4408

Mukai F, Ishiguro K, Sano Y et al (2002) Alternative splicing isoform of tau protein kinase I/glycogen synthase kinase 3beta. J Neurochem 81:1073-1083

Mukhopadhyay P, Ali MA, Nandi A et al (2006) The cyclindependent kinase 2 inhibitor down-regulates interleukin-1betamediated induction of cyclooxygenase- 2 expression in human lung carcinoma cells. Cancer Res 66:1758-1766

Murakami M, Hibi M, Nakagawa N et al (1993) IL-6-induced homodimerization of gp130 and associated activation of a tyrosine kinase. Science 260:1808-1810

Murakami H, Furihata M, Ohtsuki Y et al (1999) Determination of the prognostic significance of cyclin B1 overexpression in patients with esophageal squamous cell carcinoma. Virchows Arch 434:153-158

Nakamura T, Hayashi K, Ota M et al (2004) Expression of p21(Waf1/ Cip1) predicts response and survival of esophageal cancer patients treated by chemoradiotherapy. Dis Esophagus $17: 315-321$

Nakao T, Geddis AE, Fox NE et al (2008) PI3 K/Akt/FOXO3a pathway contributes to thrombopoietin-induced proliferation of primary megakaryocytes in vitro and in vivo via modulation of p27(Kip1). Cell Cycle 7:257-266

Niessen CM, Gottardi CJ (2008) Molecular components of the adherens junction. Biochim Biophys Acta 1778:562-571

Ohtani M, Nagai S, Kondo S et al (2008) Mammalian target of rapamycin and glycogen synthase kinase 3 differentially regulate lipopolysaccharide-induced interleukin-12 production in dendritic cells. Blood 112:635-643

Ohteki T, Parsons M, Zakarian A et al (2000) Negative regulation of $\mathrm{T}$ cell proliferation and interleukin 2 production by the serine threonine kinase GSK-3. J Exp Med 192:99-104

Oka M, Iizuka N, Yamamoto K et al (1996a) The influence of interleukin-6 on the growth of human esophageal cancer cell lines. J Interferon Cytokine Res 16:1001-1006

Oka M, Yamamoto K, Takahashi M et al (1996b) Relationship between serum levels of interleukin 6, various disease parameters and malnutrition in patients with esophageal squamous cell carcinoma. Cancer Res 56:2776-2780 
Ola MS, Nawaz M, Ahsan H (2011) Role of Bcl-2 family proteins and caspases in the regulation of apoptosis. Mol Cell Biochem 351:41-58

O'Riordan JM, Abdel-latif MM, Ravi N et al (2005) Proinflammatory cytokine and nuclear factor kappa-B expression along the inflammation-metaplasia-dysplasia-adenocarcinoma sequence in the esophagus. Am J Gastroenterol 100:1257-1264

Ougolkov AV, Fernandez-Zapico ME, Bilim VN et al (2006) Aberrant nuclear accumulation of glycogen synthase kinase3beta in human pancreatic cancer: association with kinase activity and tumor dedifferentiation. Clin Cancer Res 12:5074-5081

Ougolkov AV, Bone ND, Fernandez-Zapico ME et al (2007) Inhibition of glycogen synthase kinase-3 activity leads to epigenetic silencing of nuclear factor kappaB target genes and induction of apoptosis in chronic lymphocytic leukemia B cells. Blood 110:735-742

Pages F, Ragueneau M, Rottapel R et al (1994) Binding of phosphatidylinositol-3-OH kinase to CD28 is required for T-cell signalling. Nature 369:327-329

Park H, Li Z, Yang XO et al (2005) A distinct lineage of CD4 T cells regulates tissue inflammation by producing interleukin 17 . Nat Immunol 6:1133-1141

Patel S, Woodgett J (2008) Glycogen synthase kinase-3 and cancer: good cop, bad cop? Cancer Cell 14:351-353

Paweletz CP, Charboneau L, Bichsel VE et al (2001) Reverse phase protein microarrays which capture disease progression show activation of pro-survival pathways at the cancer invasion front. Oncogene 20:1981-1989

Peyrollier K, Hajduch E, Blair AS et al (2000) L-leucine availability regulates phosphatidylinositol 3-kinase, p70 S6 kinase and glycogen synthase kinase-3 activity in L6 muscle cells: evidence for the involvement of the mammalian target of rapamycin (mTOR) pathway in the L-leucine-induced up-regulation of system A amino acid transport. Biochem J 350(Pt 2):361-368

Pham-Nguyen KB, Yang W, Saxena R et al (1999) Role of NK and T cells in IL-12-induced anti-tumor response against hepatic colon carcinoma. Int J Cancer 81:813-819

Rehani K, Wang H, Garcia CA et al (2009) Toll-like receptormediated production of IL-1Ra is negatively regulated by GSK3 via the MAPK ERK1/2. J Immunol 182:547-553

Rossig L, Badorff C, Holzmann Y et al (2002) Glycogen synthase kinase-3 couples AKT-dependent signaling to the regulation of p21Cip1 degradation. J Biol Chem 277:9684-9689

Saito T, Kato H, Saito M et al (1994a) TNF receptor numberdependent cytotoxicity to TNF-resistant human esophageal cancer cell lines by combination with recombinant human necrosis factor and hyperthermia. Hum Cell 7:55-61

Saito Y, Vandenheede JR, Cohen P (1994b) The mechanism by which epidermal growth factor inhibits glycogen synthase kinase 3 in A431 cells. Biochem J 303(Pt 1):27-31

Sanchez JF, Sniderhan LF, Williamson AL et al (2003) Glycogen synthase kinase 3beta-mediated apoptosis of primary cortical astrocytes involves inhibition of nuclear factor kappaB signaling. Mol Cell Biol 23:4649-4662

Sarbia M, Bittinger F, Porschen R et al (1996) bcl-2 expression and prognosis in squamous-cell carcinomas of the esophagus. Int $\mathbf{J}$ Cancer 69:324-328

Sarbia M, Verreet P, Bittinger F et al (1997) Basaloid squamous cell carcinoma of the esophagus: diagnosis and prognosis. Cancer 79:1871-1878

Scully C, Bagan JV (2009) Recent advances in oral oncology 2008; squamous cell carcinoma imaging, treatment, prognostication and treatment outcomes. Oral Oncol 45:e25-e30

Shakoori A, Ougolkov A, Yu ZW et al (2005) Deregulated GSK3beta activity in colorectal cancer: its association with tumor cell survival and proliferation. Biochem Biophys Res Commun 334:1365-1373

Shaw M, Cohen P (1999) Role of protein kinase B and the MAP kinase cascade in mediating the EGF-dependent inhibition of glycogen synthase kinase 3 in Swiss 3T3 cells. FEBS Lett 461:120-124

Sheridan CM, Heist EK, Beals CR et al (2002) Protein kinase A negatively modulates the nuclear accumulation of NF-ATc1 by priming for subsequent phosphorylation by glycogen synthase kinase-3. J Biol Chem 277:48664-48676

Sugimura K, Miyata H, Tanaka K et al (2012) Let-7 expression is a significant determinant of response to chemotherapy through the regulation of IL-6/STAT3 pathway in esophageal squamous cell carcinoma. Clin Cancer Res 18:5144-5153

Suzuki M, Shinohara F, Endo M et al (2009) Zebularine suppresses the apoptotic potential of 5-fluorouracil via cAMP/PKA/CREB pathway against human oral squamous cell carcinoma cells. Cancer Chemother Pharmacol 64:223-232

Taira N, Mimoto R, Kurata M et al (2012) DYRK2 priming phosphorylation of c-Jun and c-Myc modulates cell cycle progression in human cancer cells. J Clin Invest 122:859-872

Tan J, Zhuang L, Leong HS et al (2005) Pharmacologic modulation of glycogen synthase kinase-3beta promotes p53-dependent apoptosis through a direct Bax-mediated mitochondrial pathway in colorectal cancer cells. Cancer Res 65:9012-9020

Thomas GM, Frame S, Goedert M et al (1999) A GSK3-binding peptide from FRAT1 selectively inhibits the GSK3-catalysed phosphorylation of axin and beta-catenin. FEBS Lett 458:247-251

Tong Q, Zhang W, Jin S et al (2011) The relationship between p27(kip1) expression and the change of radiosensitivity of esophageal carcinoma cells. Scand J Gastroenterol 46:173-176

Tselepis C, Perry I, Dawson C et al (2002) Tumour necrosis factoralpha in Barrett's oesophagus: a potential novel mechanism of action. Oncogene 21:6071-6081

Tsuboi K, Miyazaki T, Nakajima M et al (2004) Serum interleukin-12 and interleukin-18 levels as a tumor marker in patients with esophageal carcinoma. Cancer Lett 205:207-214

Turkson J (2004) STAT proteins as novel targets for cancer drug discovery. Expert Opin Ther Targets 8:409-422

Vallbohmer D, Lenz HJ (2006) Predictive and prognostic molecular markers in outcome of esophageal cancer. Dis Esophagus 19:425-432

van Sandick JW, Gisbertz SS, ten Berge IJ et al (2003) Immune responses and prediction of major infection in patients undergoing transhiatal or transthoracic esophagectomy for cancer. Ann Surg 237:35-43

Veeramachaneni NK, Kubokura H, Lin L et al (2004) Downregulation of beta catenin inhibits the growth of esophageal carcinoma cells. J Thorac Cardiovasc Surg 127:92-98

Verbeke S, Meignan S, Lagadec C et al (2010) Overexpression of p75(NTR) increases survival of breast cancer cells through p21(waf1). Cell Signal 22:1864-1873

Verde P, Casalino L, Talotta F et al (2007) Deciphering AP-1 function in tumorigenesis: fra-ternizing on target promoters. Cell Cycle 6:2633-2639

Voest EE, Kenyon BM, O'Reilly MS et al (1995) Inhibition of angiogenesis in vivo by interleukin 12 . J Natl Cancer Inst 87:581-586

Voronov E, Shouval DS, Krelin Y et al (2003) IL-1 is required for tumor invasiveness and angiogenesis. Proc Natl Acad Sci USA 100:2645-2650

Vujanovic NL (2001) Role of TNF family ligands in antitumor activity of natural killer cells. Int Rev Immunol 20:415-437

Wang QS, Sabourin CL, Wang H et al (1996) Overexpression of cyclin D1 and cyclin E in $N$-nitrosomethylbenzylamine-induced rat esophageal tumorigenesis. Carcinogenesis 17:1583-1588 
Wang LD, Zhou Q, Wei JP et al (1998) Apoptosis and its relationship with cell proliferation, p53, Waflp21, bcl-2 and c-Myc in esophageal carcinogenesis studied with a high-risk population in northern China. World J Gastroenterol 4:287-293

Wang LD, Zheng S, Zheng ZY et al (2003) Primary adenocarcinomas of lower esophagus, esophagogastric junction and gastric cardia: in special reference to China. World J Gastroenterol 9:1156-1164

Wang H, Garcia CA, Rehani K et al (2008) IFN-beta production by TLR4-stimulated innate immune cells is negatively regulated by GSK3-beta. J Immunol 181:6797-6802

Wang L, Yi T, Kortylewski M et al (2009) IL-17 can promote tumor growth through an IL-6-Stat3 signaling pathway. J Exp Med 206:1457-1464

Wang H, Brown J, Garcia CA et al (2011a) The role of glycogen synthase kinase 3 in regulating IFN-beta-mediated IL-10 production. J Immunol 186:675-684

Wang H, Brown J, Gu Z et al (2011b) Convergence of the mammalian target of rapamycin complex 1- and glycogen synthase kinase 3-beta-signaling pathways regulates the innate inflammatory response. J Immunol 186:5217-5226

Wang H, Brown J, Martin M (2011c) Glycogen synthase kinase 3: a point of convergence for the host inflammatory response. Cytokine 53:130-140

Wang J, Tang R, Lv M et al (2011d) Defective anchoring of JNK1 in the cytoplasm by MKK7 in Jurkat cells is associated with resistance to Fas-mediated apoptosis. Mol Biol Cell 22:117-127

Watcharasit P, Bijur GN, Song L et al (2003) Glycogen synthase kinase-3beta (GSK3beta) binds to and promotes the actions of p53. J Biol Chem 278:48872-48879

Wei W, Jin J, Schlisio S et al (2005) The v-Jun point mutation allows c-Jun to escape GSK3-dependent recognition and destruction by the Fbw7 ubiquitin ligase. Cancer Cell 8:25-33

Welsh GI, Miyamoto S, Price NT et al (1996) T-cell activation leads to rapid stimulation of translation initiation factor eIF2B and inactivation of glycogen synthase kinase-3. J Biol Chem 271:11410-11413

Wolf JS, Chen Z, Dong G et al (2001) IL (interleukin)-1alpha promotes nuclear factor-kappaB and AP-1-induced IL-8 expression, cell survival, and proliferation in head and neck squamous cell carcinomas. Clin Cancer Res 7:1812-1820

Wood JE, Schneider H, Rudd CE (2006) TcR and TcR-CD28 engagement of protein kinase $\mathrm{B}$ (PKB/AKT) and glycogen synthase kinase-3 (GSK-3) operates independently of guanine nucleotide exchange factor VAV-1. J Biol Chem 281:32385-32394

Woodgett JR (1990) Molecular cloning and expression of glycogen synthase kinase-3/factor A. EMBO J 9:2431-2438

Woodgett JR, Cohen P (1984) Multisite phosphorylation of glycogen synthase. Molecular basis for the substrate specificity of glycogen synthase kinase-3 and casein kinase-II (glycogen synthase kinase-5). Biochim Biophys Acta 788:339-347

Wu QM, Yu JP, Tong Q et al (2003) Inhibition of adenovirusmediated p27kip1 gene on growth of esophageal carcinoma cell strain. World J Gastroenterol 9:2404-2408

Yada M, Hatakeyama S, Kamura T et al (2004) Phosphorylationdependent degradation of c-Myc is mediated by the F-box protein Fbw7. EMBO J 23:2116-2125

Yan S, Zhou C, Zhang W et al (2008) beta-Catenin/TCF pathway upregulates STAT3 expression in human esophageal squamous cell carcinoma. Cancer Lett 271:85-97

Yao Z, Fanslow WC, Seldin MF et al (1995) Herpesvirus Saimiri encodes a new cytokine, IL-17, which binds to a novel cytokine receptor. Immunity 3:811-821

Yoshida S, Ono M, Shono T et al (1997) Involvement of interleukin8 , vascular endothelial growth factor, and basic fibroblast growth factor in tumor necrosis factor alpha-dependent angiogenesis. Mol Cell Biol 17:4015-4023

Zhang HY, Spechler SJ, Souza RF (2009) Esophageal adenocarcinoma arising in Barrett esophagus. Cancer Lett 275:170-177

Zhou XB, Lu N, Zhang W et al (2002) Expression and significance of beta-catenin in esophageal carcinoma. Ai Zheng 21:877-880

Zhou Y, Uddin S, Zimmerman T et al (2008) Growth control of multiple myeloma cells through inhibition of glycogen synthase kinase-3. Leuk Lymphoma 49:1945-1953 